\title{
Editorial
}

\section{Advanced Integral Type Reactors: Passive Safety Design and Experiment}

\author{
Li Shengqiang, ${ }^{1,2}$ Yanping Huang, ${ }^{3}$ Luciano Burgazzi, ${ }^{4}$ and Annalisa Manera ${ }^{5}$ \\ ${ }^{1}$ Institute of Nuclear and New Energy Technology (INET), Tsinghua University, Beijing 100084, China \\ ${ }^{2}$ Key Laboratory of Nuclear Engineering and Safety of MOE, Tsinghua University, Beijing 102201, China \\ ${ }^{3}$ Reactor Engineering Research Division, Nuclear Power Institute of China, Chengdu 610041, China \\ ${ }^{4}$ Reactor Safety and Fuel Cycle Methods Technical Unit, Italian National Agency for New Technologies, \\ Energy and Sustainable Economic Development, 40129 Bologna, Italy \\ ${ }^{5}$ Nuclear Engineering \& Radiological Sciences, University of Michigan, Ann Arbor, MI 48109-2104, USA \\ Correspondence should be addressed to Li Shengqiang; sqli@tsinghua.edu.cn
}

Received 26 August 2014; Accepted 26 August 2014

Copyright (C) 2015 Li Shengqiang et al. This is an open access article distributed under the Creative Commons Attribution License, which permits unrestricted use, distribution, and reproduction in any medium, provided the original work is properly cited.

Advanced integral type reactors are increasingly becoming a promising engineering solution for broad application of nuclear energy. A large number of prototype advanced integral reactors have been operated or are being constructed and developed in recent years, including CNP-300, KLT40S, CAREM, mPower, IRIS, NHR-200, SMART, Westinghouse SMR, ACPR100, SC-HTGR, IMR, NuScale, VBER-300, ENHS, and 4 S. The advantages of applied flexibility, economic efficiency, staffing, waste reduction, nonproliferation, and special enhanced safety features of these integral reactors may greatly improve the public acceptance and environment compatibility in future nuclear applications. To accelerate the adoption of new research productions in future applications, a number of important issues should be addressed, such as enhanced natural circulation, passive cooling, scheduling of multimodular reactors, and advanced experimental technologies. In this special issue on advanced integral reactors, we have invited a few papers that address such issues.

The paper which is named as "Natural Circulation Characteristics of a Symmetric Loop under Inclined Conditions" in this special issue addresses the full passive cooling in the primary loop under inclined conditions. Both experiments and CFD simulations have been carried out and their products are compared. The paper, which is named as "An Evaluation of SMR Economic Attractiveness," evaluates the economic attractiveness of small integral reactors, which can be assessed mainly from two frames: investment profitability and investment risk. A code which is based on the discounted cash flow was applied in the study. The paper named as "Procedure of Active Residual Heat Removal after Emergency Shutdown of High-Temperature-Gas-Cooled Reactor" presents simulation for the residual heat removal with active facilities for module gas cooling reactors. A one-dimensional model was adopted in the calculation. The possible cold/heat shock in the active loop was evaluated and the optimal strategy for the operating process was provided.

Another paper, "Design of the VISTA-ITL Test Facility for an Integral Type Reactor of SMART and a Post-Test Simulation of a SBLOCA Test," of this special issue presents a multifunction thermal-hydraulic integral effect test facility. It was designed extensively to assess the passive safety system and passive residual heat removal system for integral type reactors. Its performance and simulation capability in prototype reactors were also evaluated by MARS-KS code. Besides, the paper "Experimental Research on Passive Residual Heat Removal System of Chinese Advanced PWR" describes the serial experiments for passive residual heat removal system in Chinese advanced pressurized water reactor. A semiempirical model and a new simulation code have been developed and calibrated by experiments results. Two subsequent papers, "Some Movement Mechanisms and Characteristics in Pebble Bed Reactor" and "Experimental and Numerical Study of Stagnant Zones in Pebble Bed," concentrate on the topic of fuel pebble movement mechanisms in the pebble bed reactors. The experiments and simulation results show mixing zone was produced from pebbles' dispersion motions. 
The geometry characteristics of the dispersion regions and stagnant zones were evaluated by both experiments and DEM simulations, respectively.

Another paper, "Study on Thermal-Hydraulic Behavior of an Integral Type Reactor under Heaving Condition," presents the study on thermal-hydraulic behavior of the integral reactor under heaving conditions. The sensitive study on the effect of motion parameters on natural circulation was also investigated. The results were adopted for geometry characteristics optimization. Another paper, "Study on the Behaviors of a Conceptual Passive Containment Cooling System," proposes the new design of the passive cooling system for large dry containment. It can be applied to multimodule integral reactors. The numerical studies were performed and different operating stages were classified. The feasibility of the system for integrity containment is also discussed.

Another paper, which is named as "Operation of Shared Systems via a Common Control System in a Multi-Modular Plant," focuses on the control strategy on assemblage of integral reactors. It presents the evaluation of the module and shared control system for a group of integral type reactors in future commercial plant applications. Different characteristics of the shared system are analyzed. Different operation and control strategies are also presented. The paper "The Effect of Beam Intensity on Temperature Distribution in ADS Windowless Lead-Bismuth Eutectic Spallation Target" is more forward looking. It addresses the optimization design of spallation target for accelerator driven system, which is a promising type of future integral reactor. The nuclear physics calculation was coupled with computational fluid dynamics calculation for thermal-hydraulic study in this work. The maximum temperature and temperature distribution in the windowless target were evaluated under different beam intensity. The paper "The Stress and Reliability Analysis of HTR's Graphite Component" addresses the mechanical analysis of graphite components in the integral gas cooling reactors under high temperature and fast neutron irradiation. Different creep models and reliability models are taken into account in the simulation.

Another paper, "Single Phase Natural Circulation Behaviors of the Integral Type Marine Reactor Simulator under Rolling Motion Condition," presents the full natural circulation characteristics in the primary loop of integral reactors under rolling motion conditions. The experiments result and numerical simulation products were compared. A new system analysis code for integral type reactor under rolling conditions was developed. The paper "Research and Evaluation for Passive Safety System in Low Pressure Reactor" in this special issue addresses a passive safety system, which is under development, for integral small reactors. The performance of the passive safety system under LOCA and SBO conditions was evaluated by several tests and a best estimate thermalhydraulic code. 


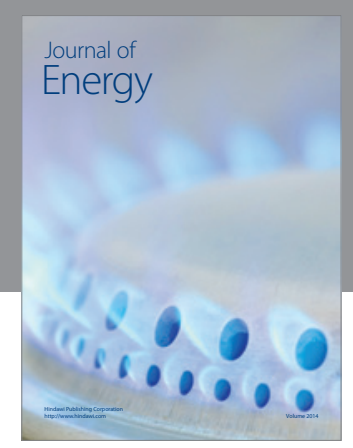

Journal of

Industrial Engineering
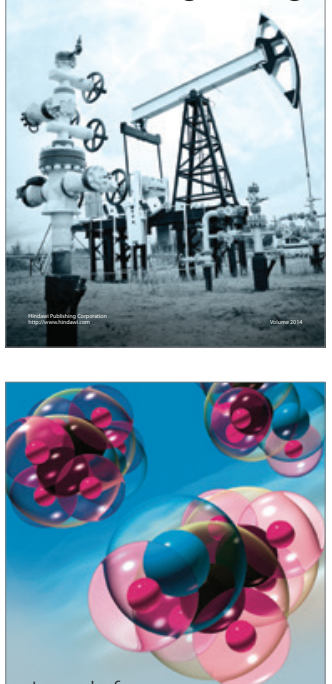

Fuels
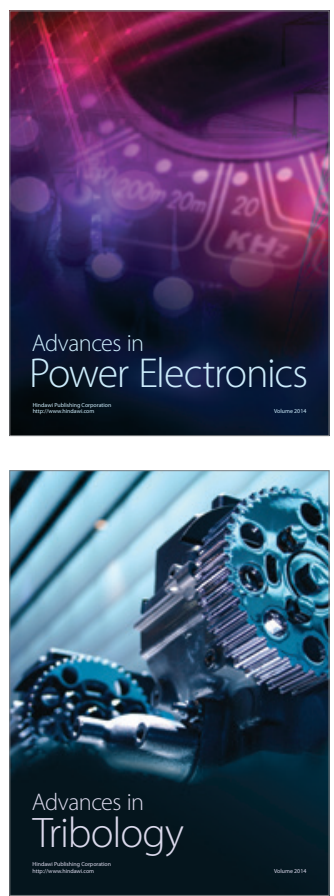

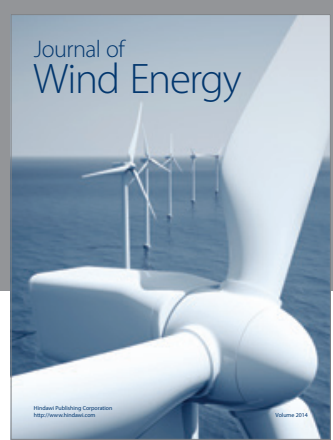

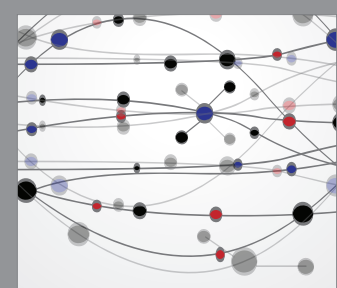

The Scientific World Journal

Submit your manuscripts at http://www.hindawi.com

Journal of

Structures
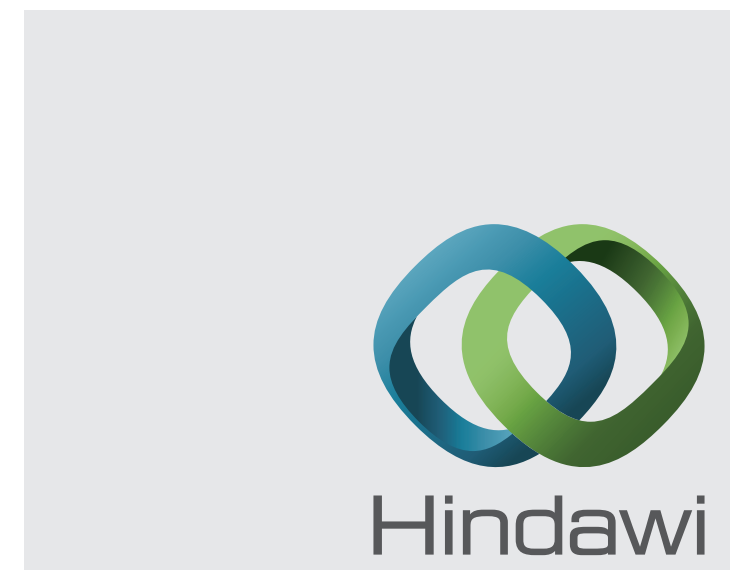

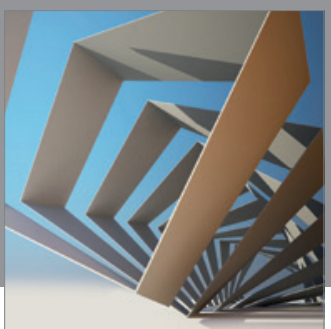

Rotating

Machinery
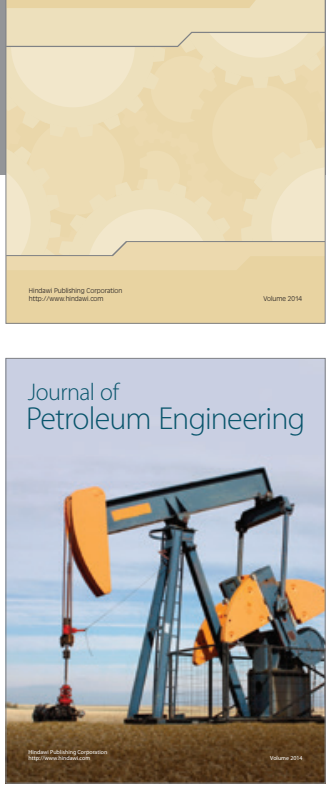

Journal of

Solar Energy
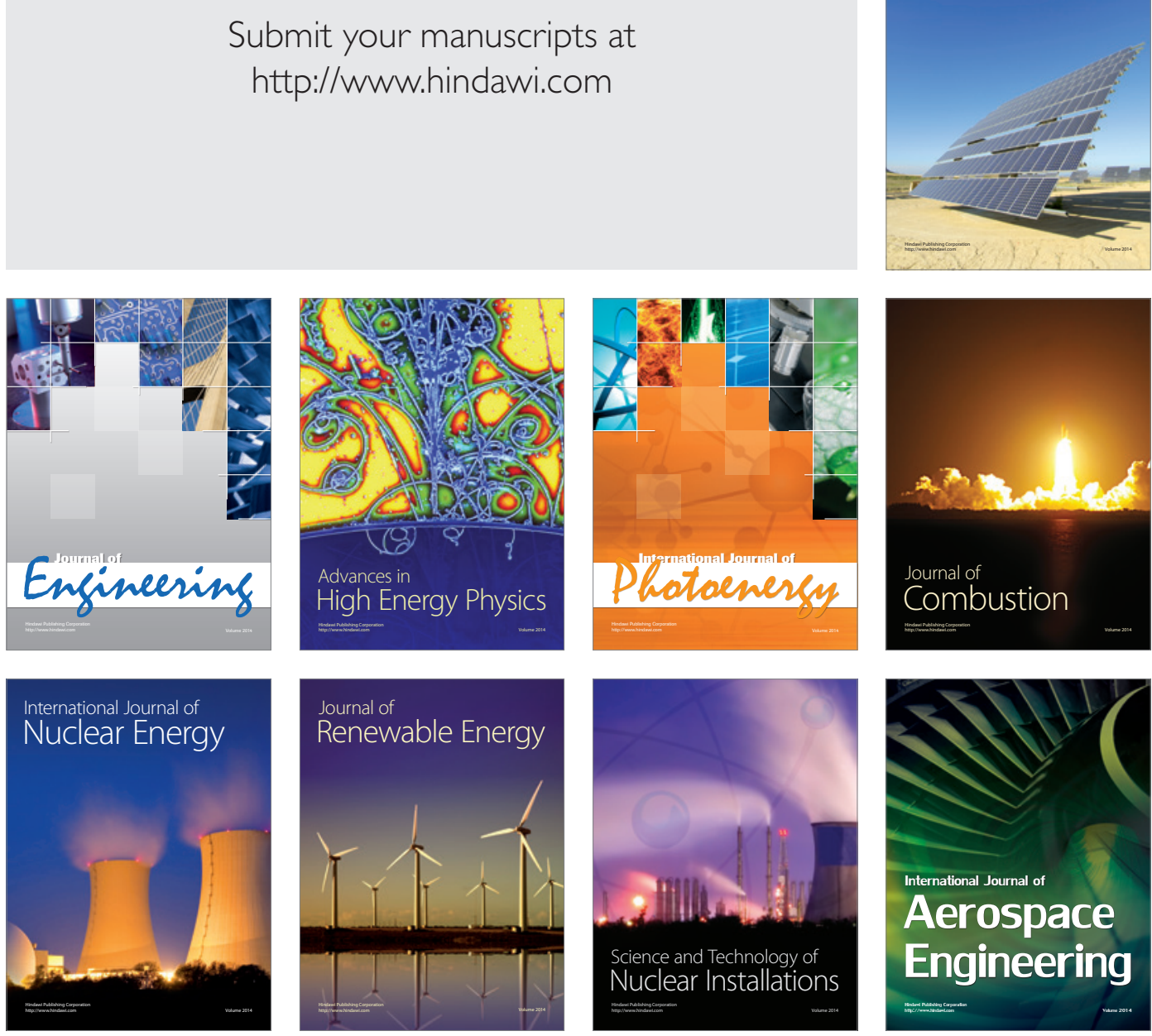